\title{
Efektifitas Akupresur dalam Menurunkan Skala Nyeri Pasien Hipertensi Diwilayah Kerja Puskesmas Perumnas
}

\author{
Sri Haryani ${ }^{1 *}$, Misniarti ${ }^{2}$ \\ ${ }^{1,2}$ Prodi Keperawatan Curup, Poltekkes Kemenkes Bengkulu, Curup, Indonesia \\ *sri.ani37@gmail.com
}

\begin{abstract}
Acupressure is a non-pharmacological therapy that can be used to reduce blood pressure in hypertensive patients and can be included in the nursing care plan. Hypertension in Indonesia is $44.1 \%$ and the mortality rate due to hypertension is $34.1 \%$. Hypertension data in Perumnas Public Health Center are 790 cases. This study aimed to determine the effect of acupressure on pain scales in hypertensive patients. This study used a quasi-experimental design with a sample size of 55 respondents with pre-post intervention. The results showed that there were differences in average pain scores between before and after acupressure intervention. Acupressure can be used to reduce pain better with a $p$ value of 0.001. Acupressure therapy has many functions for physical health, one of which is to reduce acute and chronic pain. Pain occurs due to an imbalance of "qi" energy flow in the body. Acupressure will balance the body's "qi" energy flow so that it will relieve pain while curing diseases. This study recommended that health promotion measures be carried out on families and patients so that they can carry out routine blood pressure measurements and alternative treatments with acupressure therapy to reduce complaints due to hypertension.
\end{abstract}

Keywords: acupressure, headache scale, hypertension.

\begin{abstract}
Abstrak
Akupresur merupakan salah satu therapi non farmakologis yang dapat digunakan menurunkan tekanan darah pada pasien hipertensi dan dapat dimasukkan dalam rencana asuhan keperawatan. Hipertensi di Indonesia terdapat sebesar 44,1\% dan angka kematian karena hipertensi sebanyak 34,1\%. Data hipertensi diPuskesmas Perumnas sebanyak 790 kasus. Penelitian ini bertujuan untuk mengetahui efektifitas akupresur terhadap skala nyeri pada pasien hipertensi. Penelitian ini menggunakan desain quasi experiment dengan besar sampel 55 responden dengan intervensi pre post. Hasil penelitian menunjukkan bahwa terdapat perbedaan rata-rata skor nyeri antara sebelum dengan setelah diberikan intervensi akupresur. Akupresur dapat digunakan untuk mengurangi nyeri lebih baik dengan $p$ value 0,001 . Terapi akupresur memiliki banyak fungsi bagi kesehatan tubuh salah satunya adalah menurunkan nyeri akut maupun kronis. Nyeri terjadi karena adanya ketidakseimbangan aliran energi "qi" di dalam tubuh. Akupresur akan menyeimbangkan aliran energi "qi" tubuh sehingga akan menghilangkan rasa nyeri sekaligus menyembuhkan penyakit. Penelitian ini direkomendasikan untuk dilakukannya tindakan promosi kesehatan pada keluarga dan pasien agar dapat melakukan pengukuran tekanan darah secara rutin serta melakukan pengobatan alternatif dengan therapi akupresur untuk mengurangi keluhan akibat hipertensi.
\end{abstract}

Kata Kunci: akupresur, skala nyeri kepala, hipertensi.

Jurnal Keperawatan Raflesia, Volume 2 Nomor 1, Mei 2020

ISSN: (p) 2656-6222, (e) 2657-1595, DOI 10.33088/jkr.v2i1.491

Available online: https://jurnal.poltekkes-kemenkes-bengkulu.ac.id/index.php/jkr 


\section{PENDAHULUAN}

Tekanan darah tinggi atau hipertensi dapat dikatakan sebagai the silent killer yang merupakan penyakit tanpa gejala atau pembunuh secara diam-diam yang menjadi salah satu penyumbang angka kematian akibat penyakit yang tidak menular (PTM) dan merupakan masalah kesehatan yang serius tidak hanya di Indonesia tetapi juga didunia (Hasnah, 2016). Tahun 2025 WHO memperkirakan sekitar 29\% atau sekitar 1 miliar warga dunia menderita hipertensi, negara dengan ekonomi yang berkembang memiliki sekitar $40 \%$ penderita hipertensi. Hipertensi dikawasan Asia, telah menyebabkan 1,5 juta manusia meninggal dalam satu tahunya dan menimbulkan berbagai macam komplikasi terhadap penderita hipertensi (Widiyani 2013 dalam Tarigan, 2018).

Menurut hasil Riskesdas 2017 sebanyak $34,1 \%$ penduduk Indonesia usia 18 tahun keatas terdiagnosis hipertensi dengan prevalensi hipertensi tertinggi didaerah Kalimantan Selatan sebesar $(44,1 \%)$ dan terendah sebesar $(22,2 \%)$ di Papua. Angka kematian yang disebabkan oleh hipertensi yaitu 427.218 (Kemenkes RI, 2017). Pada tahun 2016 jumlah warga Bengkulu yang didiagnosa hipertensi berjumlah 5.263 orang (14,95\%) (Profil Kesehatan Bengkulu, 2016). Pada tahun 2017 data hipertensi di Kabupaten Rejang Lebong mencapai 1175 jiwa dengan penyumbang angka kematian sebanyak 84 jiwa. Tingkat kejadian hipertensi dialami oleh umur 1875 pada wanita sebanyak 814 kasus dan 359 kasus dialami oleh pria (Dinas Kesehatan Rejang Lebong, 2017). Menurut data dari Puskesmas Perumnas Kabupaten Rejang Lebong sebanyak 790 kasus hipertensi (Laporan Puskesmas Perumnas 2017).

Hipertensi merupakan peningkatan tekanan darah pada sistolik lebih besar atau sama dengan $\geq 140 \mathrm{mmHg}$ dan atau tekanan diastolik $\geq 90 \mathrm{mmHg}$ (untuk usia $\geq 60$ tahun). Tingginya angka hipertensi disebabkan oleh faktor antara lain, genetik, Pil KB, usia, jenis kelamin, stress, geografi, lingkungan, gaya atau pola hidup, garam dapur, dan merokok. Jika pasien yang telah lama terdiagnosa hipertensi dan tidak diobati akan menyebabkan komplikasi antara lain, stroke, serangan jantung, gagal jantung, gagal ginjal kronik, dan mata (retinopati hipertensif). Beberapa pasien yang menderita hipertensi biasanya mengalami tanda dan gejala seperti, sakit kepala parah, penglihatan kabur, telinga berdenging, kebingungan, detak jantung tidak teratur, nyeri dada, pusing, lemas, kelelahan, sulit bernafas, gelisah, mual atau muntah, epistaksis, terdapat darah dalam urin, peningkatan vena jugularis dan kesadaran menurun (Wijaya \& Putri, 2013). Nyeri merupakan gejala yang menjadi salah satu manifestasi klinis oleh penderita hipertensi. Nyeri merupakan pengalaman sensorik dan emosional dimana seseorang yang mengalami nyeri merasa tidak nyaman dan nyeri hanya dapat dirasakan oleh penderita tersebut atau bersifat subjektif, untuk itu pasien dan keluarga pasien perlu mendapatkan informasi dari perawat mengenai terapi non farmakologi yang dapat membantu mengurangi skala nyeri akibat hipertensi. Pasien diharuskan memodifikasi gaya hidup, seperti penurunan berat badan, mengatur jadwal olahraga dan diet hipertensi.

Salah satu pengobatan yang dapat dilakukan oleh pasien selain pengobatan 
medis yaitu dengan melakukan terapi modalitas yang berkembang saat ini mencakup terapi psikofarmakologi, terapi perubahan perilaku dan kognitif, terapi manajemen agresi, terapi somatik, terapi komplementer dan alternative, terapi kelompok terapeutik dan terapi keluarga (Susana et al. 2007 dalam Astuti, 2017). Pengobatan komplementer bertindak sebagai pilihan terapi yang baik untuk mengobati berbagai penyakit dan dapat meningkatkan kualitas hidup dengan mempertimbangkan aspek ekonomi. Akupresur berasal dari Tiongkok kuno didasarkan pada prinsip aktivasi acupoint di seluruh meridian yang mengoreksi ketidakseimbangan antara Qi. Aktivasi titik-titik spesifik pada meridian dikenal untuk memfasilitasi pengurangan rasa sakit di situs lokal (Mehta, 2017).

Akupresur merupakan salah satu therapi non farmakologis dapat menurunkan tekanan darah pada pasien hipertensi dan dapat dimasukkan dalam rencana asuhan keperawatan untuk hipertensi (Hon etc, 2016). Akupresur dengan Taixi (Ki3) dan Sanyinjiao (SP6) effektive menurunkan tekanan darah di PSTW Jember. Terapi akupresur yang dilakukan akan menstimulasi sel saraf sensorik disekitar titik akupresur akan diteruskan kemedula spinalis, kemudian ke mesensefalon dan komplek pituitari hipothalamus yang ketiganya diaktifkan untuk melepaskan hormon endorfin yang dapat memberikan rasa tenang dan nyaman. Akupresur juga menstimulasi pelepasan histamin yang berpengaruh pada vasodilatasi pembuluh darah, kedua manfaat akupresur tersebut dapat menurunkan tekanan darah lansia (Majid dkk, 2016). Terapi akupresur memiliki banyak fungsi bagi kesehatan tubuh salah satunya adalah menurunkan nyeri akut maupun kronis. Nyeri terjadi karena adanya ketidakseimbangan aliran energi "qi" di dalam tubuh. Akupresur akan menyeimbangkan aliran energi "qi" tubuh sehingga akan menghilangkan rasa nyeri sekaligus menyembuhkan penyakit yang diderita (Kurniyawan, 2016). Priyo (2018) menyatakan adanya penurunan tekanan darah maupun nyeri pada klien lansia hipertensi dengan akupresur.

Berdasarkan data dan hasil penelitian diatas, maka peneliti melakukan studi pendahuluan untuk mendapatkan gambaran umum pasien dengan nyeri kepala karena hipertensi di Puskesmas Perumnas Kabupaten Rejang Lebong melalui wawancara langsung pada pasien hipertensi yang melakukan kontrol dan berobat. Peneliti menemukan bahwa 3 dari 5 pasien mengalami nyeri kepala dengan tingkatan nyeri ringan, sedang sampai berat dengan karakteristik nyeri yang berbedabeda seperti ditekan, ditusuk dan kepala yang terasa berat, sehingga saat nyeri kepala mereka akan membatasi aktifitas sehari-hari serta mereka mengeluhkan minum obat hipertensi setiap hari bosan, lupa, dan malas ke puskesmas untuk kontrol dan mengambil obat, sehingga peneliti memberikan alternatif pengobatan lain untuk mengurangi gejala yang mereka alami dengan melakukan pengobatan komplementer akupresur. Berdasarkan data kejadian diatas dan fenomena yang terjadi, peneliti tertarik untuk melakukan penelitian tentang "Efektifitas Akupresur Terhadap Penurunan Skala Nyeri Kepala Pada Pasien Hipertensi di Wilayah Kerja Puskesmas Perumnas Kabupaten Rejang Lebong Tahun 2018". 


\section{METODE}

Desain dalam penelitian ini menggunakan desain penelitian quasi experiment dengan menggunakan pretest-postest with control group (rancangan pretest-postest dengan kelompok kontrol) (Dharma, 2011). Populasi yang digunakan dalam penelitian adalah semua pasien hipertensi yang berobat atau kontrol di Puskesmas Perumnas berjumlah 790 orang pada tahun 2017. Adapun total sampel pada penelitian ini adalah 55 orang yang terdiri dari 30 orang kelompok intervensi dan 25 kelompok kontrol. Tehnik yang digunakan consecutive sampling, dalam pengambilan sampel dalam penelitian ini yang merupakan jenis non-probability sampling (Sastroasmoro \& Ismail, 2011).

Kriteria inklusi dalam penelitian ini adalah: Bersedia menjadi responden penelitian, tekanan darah sistolik besar atau sama dengan $140 \mathrm{mmHg}$ dan atau tekanan diastolik $\geq 90 \mathrm{mmHg}$ dan mengalami nyeri kepala saat pengambilan data yang dinilai dengan pengukuran skala nyeri PQRST.

Pada kelompok intervensi diberikan therapi akupresur, sedangkan untuk kelompok kontrol diberikan buklet tentang cara perawatan hipertensi dirumah yang dapat digunakan untuk menambah pengetahuan klien dalam melakukan perawatan untuk menurunkan nyeri kepala saat tekanan darahnya meningkat. Akupresur dilakukan pada titik regio kepala, ekstra dan juga dilakukan diluar dua titik tersebut. Pemijatan ini dilakukan minimal 50 kali tekanan dengan berlawanan jarum jam.
Instrumen yang digunakan dalam penelitian ini ada 2, instrumen A berupa karakteristik responden yang dibuat oleh peneliti, dan instrumen B untuk mengukur skala nyeri yang menggunakan skala numerik dengan metode PQRST yang diadopsi dari Sudoyo, (2006), serta SOP untuk melakukan tindakan akupresur yang dilakukan oleh perawat yang telah mengikuti pelatihan akupresur.

Data dalam penelitian ini didapatkan dari kuesioner karakteristik responden dan hasil pengukuran skala nyeri awal yang merupakan data primer, serta data sekunder didapatkan dari laporan tahunan Puskesmas Perumnas Tahun 2017.

Analisa data menggunakan uji univariat dan uji bivariat. Uji yang digunakan untuk menguji hipotesis nyeri kepala hipertensi pada kelompok intervensi dan kontrol dan perbedaan selisih rerata nyeri kepala antara kedua kelompok yang sama sebelum dan sesudah intervensi pada masing-masing kelompok menggunakan uji $t$ paired, sedangkan untuk menguji perbedaan mean nyeri kepala pada kelompok yang berbeda serta melihat selisih skala nyeri kepala hipertensi pada kelompok intervensi dan kontrol menggunakan uji independent $t$ test.

Penelitian ini telah lulus uji etik dari Komisi Etik Penelitian Kesehatan Poltekkes Kemenkes Bengkulu 


\section{HASIL}

Tabel 5.1

\section{Gambaran Karakteristik Responden Dan Kesetaraan Pasien hipertensi Sebelum Dilakukan Intervensi Akupresur Di Wilayah Kerja Puskesmas Perumnas Tahun 2018}

\begin{tabular}{|c|c|c|c|}
\hline \multirow{2}{*}{ Variabel } & \multicolumn{2}{|c|}{ Kelompok } & \multirow{2}{*}{$\begin{array}{c}p \\
\text { value } \\
\end{array}$} \\
\hline & $\begin{array}{c}\text { Intervensi } \\
(\mathrm{n}=30)\end{array}$ & $\begin{array}{c}\text { Non } \\
\text { Intervensi } \\
(\mathrm{n}=25)\end{array}$ & \\
\hline Umur, mean (SD) & $26,3(3,4)$ & $27,5(5,2)$ & 0,404 \\
\hline Median & 45 & 40 & \\
\hline Min-maks & $17-70$ & $19-80$ & \\
\hline CI $95 \%$ & 25,$1 ; 27,5$ & 25,$5 ; 29,5$ & \\
\hline \multicolumn{4}{|l|}{ J Kelamin } \\
\hline Perempuan & $16(53,3)$ & $11(44)$ & 0,348 \\
\hline Laki-laki & $14(46,7)$ & $14(56)$ & \\
\hline \multicolumn{4}{|l|}{ Pendidikan } \\
\hline Rendah & $19(63,4)$ & $17(68)$ & 0,745 \\
\hline Tinggi & $11(36,6)$ & $8(32)$ & \\
\hline \multicolumn{4}{|l|}{ Pekerjaan } \\
\hline Bekerja & $21(70)$ & $19(76)$ & 0,135 \\
\hline Tidak Bekerja & $9(30)$ & $6(24)$ & \\
\hline
\end{tabular}

Usia untuk kelompok intervensi menunjukkan bahwa responden berada pada rentang 17-70 dan pada kelompok kontrol rata-rata usia 40 tahun, Responden untuk kelompok intervensi mayoritas berjenis kelamin perempuan yaitu 53,3\% dan untuk kontrol sebanyak 56\%. Lebih dari setengah responden memiliki tingkat pedidikan rendah yaitu $63,4 \%$ pada kelompok intervensi dan untuk kelompok kontrol sebanyak 68\%. Sebagian besar responden bekerja untuk kelompok intervensi yaitu $70 \%$ dan $76 \%$ untuk kelompok kontrol.
Tabel 5.2

Gambaran Kesetaraan Skala Nyeri Pasien Hipertensi Sebelum Dilakukan Akupresur di Wilayah Kerja Puskesmas Perumnas Tahun 2018

\begin{tabular}{llll}
\hline Variabel & \multicolumn{3}{c}{ Kelompok } \\
\hline & $\begin{array}{l}\text { Intervensi } \\
(\mathrm{n}=30)\end{array}$ & $\begin{array}{l}\text { Non } \\
\text { Intervensi } \\
(\mathrm{n}=25)\end{array}$ & $\begin{array}{l}P \\
\text { value }\end{array}$ \\
\hline Skor Total & $125,2(11,1)$ & $121(9,2)$ & 0,111 \\
Skala Nyeri & & & \\
$\quad$ Nyeri Ringan & $33,4(3,5)$ & $28,7(2,4)$ & 0,625 \\
Nyeri Sedang & $33,7(4,1)$ & $30,1(3,5)$ & 0,839 \\
Nyeri Berat & $22,7(2,1)$ & $22,3(2,4)$ & 0,930 \\
\hline
\end{tabular}

Hasil dari uji kesetaraan ini dilakukan sebelum melakukan intervensi akupresur pada kelompok intervensi dan kontrol. Skala nyeri pada pasien hipertensi ini dilihat dari tiga tingkatan skala nyeri yaitu nyeri ringan, sedang dan berat sesuai pada tabel diatas.

Tabel 5.3

Perbedaan Skala Nyeri Kepala Pasien Hipertensi Sebelum dan Sesudah dilakukan Akupresur di Wilayah Kerja Puskesmas Perumnas Tahun 2018

\begin{tabular}{|c|c|c|c|c|c|}
\hline \multirow[t]{2}{*}{ Perlakuan } & \multicolumn{2}{|c|}{ Sebelum } & \multicolumn{2}{|c|}{ Sesudah } & $p$ value \\
\hline & $\begin{array}{l}X \pm \\
S D\end{array}$ & $\begin{array}{l}\text { Min- } \\
\text { Mak }\end{array}$ & $\mathrm{X} \pm \mathrm{SD}$ & $\begin{array}{l}\text { Min- } \\
\text { Mak }\end{array}$ & \\
\hline Intervensi & $\begin{array}{c}8,64 \\
\pm \\
0,952\end{array}$ & $5-10$ & $4,4 \pm 1,472$ & $2-7$ & 0,001 \\
\hline $\begin{array}{l}\text { Non } \\
\text { Intervensi }\end{array}$ & $\begin{array}{c}6,27 \\
\pm \\
1,258\end{array}$ & $4-9$ & $4,9 \pm 1,269$ & $3-7$ & 0.061 \\
\hline
\end{tabular}

Tabel 5.3 menunjukkan bahwa pada kelompok yang diberikan intervensi memiliki efektifitas lebih baik dalam menurunkan skala nyeri dengan $p$ value 0,001 . 
Tabel 5.4

Perbedaan Skala Nyeri Sebelum dan Sesudah Intervensi Akupresur di Wilayah

Kerja Puskesmas Perumnas Tahun 2018

\begin{tabular}{|c|c|c|c|c|c|}
\hline \multirow{4}{*}{$\begin{array}{l}\text { Variabel } \\
\text { Nyeri }\end{array}$} & \multicolumn{5}{|c|}{ Skala Nyeri } \\
\hline & Sebelum & Sesudah & Selisih & $p$ & Efektifitas \\
\hline & Intervensi & Intervensi & $(\mathrm{C}-\mathrm{A})$ & value & $(\%)$ \\
\hline & & & $\begin{array}{c}\text { Mean } \\
\text { (SD) }\end{array}$ & & \\
\hline
\end{tabular}

\begin{tabular}{llllll} 
Intervensi & $30,6(4,4)$ & $35,1(3,5)$ & $4,5(2,9)$ & 0,000 & 14,1 \\
Kontrol & $29,7(4,2)$ & $38,5(2,4)$ & $8,7(4,0)$ & & \\
\hline & & & & & \\
Intervensi & $33,7(4,1)$ & $41,3(2,8)$ & $7,6(2,5)$ & 0,017 & 5,9 \\
Kontrol & $33,8(4,1)$ & $43,3(1,5)$ & $9,6(3,6)$ & & \\
\hline & & & & \\
Intervensi & $22,7(2,2)$ & $28,4(2,1)$ & $5,5(1,9)$ & 0,031 & 5,8 \\
Kontrol & $22,3(2,4)$ & $29,1(2,4)$ & $6,8(2,2)$ & & \\
\hline
\end{tabular}

Tabel 5.4 terdapat perbedaan yang signifikan rerata skala nyeri ringan, sedang dan berat pasien hipertensi kelompok intervensi dan kelompok kontrol setelah diberikan intervensi. Intervensi akupresur efektif untuk menurunkan skala nyeri ringan sebesar $14,1 \%$ dan nyeri sedang $5,9 \%$ setelah 1 minggu.

\section{PEMBAHASAN}

Hasil penelitian mengenai karakteristik responden ditemukan bahwa, umur, jenis kelamin, pendidikan, dan pekerjaan antara kelompok intervensi dan kontrol berdasarkan analisis statistik didapatkan ada perbedaan yang signifikan dengan nilai $p$ value lebih besar $\alpha=0,05$, sehingga dapat disimpulkan bahwa tidak ada perbedaan karakteristik responden antara kelompok intervensi atau kelompok kontrol sebelum dilakukan intervensi.

Hasil menunjukkan bahwa usia responden untuk skala nyeri kepala dengan nilai $p$ value 0,404 , ini sesuai dengan tingginya kejadian hipertensi yang disebabkan oleh beberapa faktor. Faktor resiko hipertensi antara lain, genetik, Pil KB, usia, jenis kelamin, stress, geografi, lingkungan, gaya atau pola hidup, garam dapur, dan merokok. Menurut Wijaya \& Putri (2013) seiring bertambahnya usia seseorang, cenderung akan meningkatkan tekanan darah yang memungkinkan untuk terjadinya hipertensi dan umumnya terjadi pada usia diatas 45 tahun, namun tidak menutup kemungkinan akan diderita oleh individu yang berusia muda.

Hasil penelitian menunjukkan bahwa jenis kelamin berhubungan dengan skala nyeri kepala pada pasien hipertensi. Ini sesuai dengan Kresnawan (2011), yang menyatakan bahwa jenis kelamin perempuan akan berisiko $31,5 \%$ untuk terjadinya hipertensi dibandingkan lakilaki. Sesuai dengan Yang, et all, (2006) perempuan memiliki resiko $16,1 \%$ untuk terjadinya hipertensi. Tetapi menurut Sihombing (2010), jenis kelamin laki-laki memiliki resiko lebih besar 1,09\% untuk terjadinya hipertensi dibandingkan perempuan. Jenis kelamin perempuan memiliki resiko yang lebih besar karena dipengaruhi oleh penggunaan kontrasepsi oral secara terus-menerus.

Faktor lain yang mempengaruhi skala nyeri kepala pada pasien hipertensi yaitu pekerjaan. Dimana individu yang bekerja 51 jam per minggu lebih memungkinkan untuk terjadinya hipertensi (Yang, et all, 2006). Sejalan dengan Kresnawan (2011) individu yang bekerja berisiko 31,1 \% dibandingkan individu yang tidak bekerja. Sedangkan menurut Landsbergis (2008) usia dewasa yang bekerja memiliki risiko 10-30\% untuk terjadinya hipertensi. 
Hasil menunjukkan nilai $p$ value 0,001 yang berarti bahwa terapi akupresur dapat menurunkan skala nyeri kepala pasien hipertensi. Penurunan skala nyeri ini sesuai dengan Priyo (2018) menyatakan adanya penurunan tekanan darah maupun nyeri pada klien lansia hipertensi dengan akupresur. Dimana nyeri kepala merupakan salah satu tanda dan gejala yang dialami oleh pasien hipertensi yang ditandai dengan nyeri kepala (Nurarif, 2015). Sehingga salah satu tindakan yang dapat dilakukan untuk menurunkan nyeri yaitu dengan melakukan akupresur yang menggunakan titik untuk menurunkan nyeri kepala dengan diawali meningkatnya stamina tubuh, melancarkan peredaran darah, mengurangi stress sehingga nyeri dapat berkurang. Pijat merupakan terapi yang berkembang kedalam dua arah yaitu masase atau pijat yang termasuk kedalam disiplin ilmu akupresur yang merupakan salah satu pengobatan alternatif atau komplementer (Kumar, 2009).

Akupresur merupakan istilah yang digunakan pada titik tertentu ditubuh dengan menggunakan jari, tangan atau bagian tubuh lainnya, untuk menstimulasi titik-titik energi yang tujuannya agar seluruh organ tubuh memperoleh aliran energi vital yang cukup berbeda dengan akupunture yang menggunakan jarum sebagai alat bantu terapi (Kemenkes RI, 2015). Aktivasi titik-titik spesifik pada meridian ini dikenal untuk memfasilitasi pengurangan rasa sakit di situs lokal (Mehta, 2017). Tindakan akupresur akan menyeimbangkan aliran energi "qi" tubuh sehingga akan menghilangkan rasa nyeri sekaligus menyembuhkan penyakit yang diderita (Kurniyawan, 2016), sehingga tindakan ini harus dilakukan oleh orang yang ahli agar mendapatkan hasil yang maksimal. Sebelum tindakan dilakukan harus ditentukan terlebih dahulu titik meridian yang tepat baru pijatan bisa dilakukan, agar mendapatkan reaksi pada titik pijatan berupa rasa linu, nyeri dan pegal. Terapi akupresur dapat dilakukan dengan menggunakan jari pada bagian jempol dan telunjuk. Lama pijatan tergantung pada jenis pijatan yang dilakukan pada pijatan (yang) dilakukan maksimal 30 kali tekanan pada masingmasing titik dengan pemijatan searah jarum jam berfungsi untuk penyakit yang dingin, lemah, dan lesu. Sedangkan pada pemijatan (yin) yang berfungsi untuk melemahkan dapat dilakukan 50 kali tekanan dan pemijatannya berlawanan arah jarum jam, digunakan pada kasus penyakit panas, muka merah, kuat, dan berlebihan atau hiper (Fengge, 2012).

Penurunan skala nyeri yang dialami oleh pasien dipengaruhi oleh usia, jenis kelamin dan pekerjaan dari penderita. Sukanta (2011), tindakan akupresur dapat dilakukan menyesuaikan dengan kondisi fisik yang sedang dialami oleh pasien seperti: pencegahan, penyembuhan, rehabilitasi dan promotif. Tindakan ini dianggap lebih efektif untuk menangani masalah yang sedang dikeluhkan oleh pasien sehingga dapat menjalani hidup secara optimal. Tindakan akupresur ini menggunakan tekanan pada area titik-titik tertentu, seperti jalur meridian umum dan meridian istimewa. ADA (2017) mengatakan bahwa tindakan akupresur dapat juga digunakan untuk membantu mengurangi nyeri pada pasien dengan nyeri punggung.

Nyeri merupakan respon subjektif terhadap stressor fisik dan psikologis (Lemone, 2016), dimana terapi akupresur yang dilakukan akan menstimulasi sel saraf 
sensorik disekitar titik akupresur yang akan diteruskan ke medula spinalis, kemudian ke mesensefalon dan komplek pituitari hipothalamus yang ketiganya diaktifkan untuk melepaskan hormon endorfin yang dapat memberikan rasa tenang dan nyaman. Akupresur juga menstimulasi pelepasan histamin yang berpengaruh pada vasodilatasi pembuluh darah, dimana kedua manfaat akupresur tersebut dapat menurunkan tekanan darah pada lansia (Majid dkk, 2016). Tindakan akupresur ini harus dilakukan pada ruangan yang tenang, tidak panas atau dingin, serta tidak berasap. Selain itu tindakan akupresur tidak boleh dilakukan pada klien dalam keadaan terlalu lapar ataupun kenyang. Hal yang harus diperhatikan pada saat terapi dilakukan yaitu lingkungan tidak boleh terlalu dingin ataupun berasap (Sukanta, 2011).

\section{KESIMPULAN}

Hasil penelitian menunjukkan bahwa karakteristik responden kelompok intervensi berada pada rentang usia 17-70 tahun dan pada kelompok kontrol rata-rata usia 40 tahun. Responden untuk kelompok intervensi mayoritas berjenis kelamin perempuan yaitu 53,3\%, lebih dari sebagian responden memiliki pendidikan rendah $63,3 \%$ dan sebagian besar responden bekerja sebanyak $70 \%$. Tindakan akupresur efektif untuk menurunkan nyeri kepala pada klien hipertensi.

Perlunya dilakukan pendidikan kesehatan secara terjadwal oleh perawat yang berada di masyarakat dan adanya pemberdayaan dari kader kesehatan untuk dapat menjadi pioner dalam tindakan mengontrol tekanan darah, sehingga pasien yang mengalami nyeri kepala akibat tekanan darah yang meningkat dapat melakukan tindakan dengan kontrol tekanan darah secara rutin dan melakukan pengobatan medis serta melakukan pengobatan komplementer agar masalah yang dialami dapat teratasi.

\section{DAFTAR PUSTAKA}

ADA. (2017). Standards of medical mare in diabetes. The Journal of Clinical and Applied Research and Education. American Diabetes Association. doi: 10.2337/dc16-S003.

Astuti, R. T. (2017). Penggunaan terapi modalitas dan komplementer dalam praktek keperawatan berbasis evidence based. Diunduh dari https://www.researchgate.net/publicatio n/319929971_PENGGUNAAN_TERA PI_MODALITAS_DAN_KOMPLEM ENTER_DALAM_PRAKTEK_KEPE RAWATAN_BERBASIS_EVIDENCE _BASED. Diakses tanggal 26 Desember 2018.

Dharma, K. K. (2011). Metodologi penelitian keperawatan panduan melaksanakan dan menerapkan hasil penelitian. TIM.

Dinas Kesehatan Kabupaten Rejang Lebong. (2017). Laporan rekapitulasi kasus penyakit tidak menular Tahun 2017. Dinkes Kabupaten Rejang Lebong.

Dinas Kesehatan Provinsi Bengkulu. (2016). Profil kesehatan provinsi Bengkulu Tahun 2016. Bengkulu: Dinkes Provinsi Bengkulu.

Fengge, Antoni. (2012). Terapi akupresur manfaat dan teknik pengobatan. Corp Circle Corp.

Hasnah \& Ekawati, D. (2016). Pengaruh terapi akupunture pada pasien hipertensi dibalai kesehatan tradisonal masyarakat makkasar. Journal of islamic nursing (JOIN), 1(1). journal.uinalauddin.ac.id/index.php/join/ article/view/3505. 
Hon Lin Gan., Wei-Chun Chang., Kuan-Ju Chen., Chen-Chen Tsai.,Sung-Yuan $\mathrm{Hu}$.,and $\mathrm{Li}-\mathrm{Li}$ Chen. Effectiveness of acupressure on the taichong acupoint in lowering blood pressure in patients with hypertension: A randomized clinical trial. (2016). Evidence-Based Complementary and Alternative Medicine.Article ID 1549658, 9 pages http://dx.doi.org/10.1155/2016/1549658.

Kemenkes RI (2015). Terapi komplementer. Jakarta.

Kemenkes RI (2017). Profil Kesehatan Indonesia Tahun 2016. Jakarta.

Kresnawan, T. (2011). Asuhan gizi pada hipertensi. Journal of the Indonesian Nutrition Association, 34(2).

Kumar, V. (2009). Pijat refleksi. Jakarta: BIP Kelompok Gramedia.

Kurniyawan, E. H. (2016). Narrative review: Terapi komplementer alternatif akupresur dalam menurunkan tingkat nyeri. NurseLine Journal, 1(2), https://scholar.google.co.id/scholar.

Landsbergis. P. A., Schnall. P. L., Belki, K. L., Schwartz, J. E., Baker, D., \& Pickerin, T. G. (2008). Work conditions and masked (hidden) hypertension - insights into the global epidemic of hypertension. SJWEH Suppl, (6):41-51.

Lemone, Priscila., Burke, Keren, M., dan Gerene Bauldoff. (2016). Buku ajar keperawatan medikal bedah. Jakarta: EGC.

Majid, Y.A., \& Rini, P. S. (2016). Terapi akupresur memberikan rasa tenang dan nyaman serta mampu menurunkan tekanan darah lansia. Jurnal Aisyah: Jurnal Ilmu Kesehatan, 1(1). https://aisyah.journalpress.id/index.php/j ika/article/view/MR

Mehta, P., Dhapte, V., Kadam, S., \& Dhapte, V. (2017). Contemporary acupressure therapy: Adroit cure for painless recovery of therapeutic ailments. http://www.elsevier.com/locate/j tcme
Nurarif, Amin Huda., \& Kusuma, Hardi. (2015). Aplikasi asuhan keperawatan berdasarkan diagnosa medis dan NANDA NIC-NOC. Yogyakarta: Media Action.

Priyo, Margono, Hidayah, Nurul. (2018). Efektifitas relaksasi autogenik \& akupresur menurunkan sakit kepala \& tekanan darah pada lansia hipertensi. PROFESI (Profesional Islam): Media Publikasi Peenelitian, 15(2).

Puskesmas Perumnas. (2017). Laporan Puskesmas tahun 2017. Curup

Riset Kesehatan Dasar. (2017). RISKESDAS 2017. Jakarta: Kementerian Kesehatan Republik Indonesia.

Sastroasmoro, S., \& Ismail, S. (2011). Dasardasar metodologi penelitian klinis. (Edisi $\mathrm{Ke}-4$ ). Jakarta: Sagung Seto.

Sihombing, M. (2010). Hubungan perilaku merokok, konsumsi makanan/ minuman, dan aktivitas fisik dengan penyakit hipertensi pada responden obes usia dewasa di Indonesia. e-Jurnal Kedokteran Indonesia, 60(9), 406-412.

Sudoyo, A. W., Setiyohadi, B., Alwi, I., Marcellus S., \& Siti, S. (2006). Buku ajar ilmu penyakit dalam. (Edisi IV). Jakarta: Fakultas Kedokteran Universitas Indonesia.

Sukanta, Putu Okta. (2011). Pijat akupresur untuk kesehatan. Depok: Penebar Plus

Tarigan, R. (2018). Pengaruh pengetahuan, sikap dan dukungan keluarga terhadap diet hipertensi di desa Hulu Kecamatan Pancur Batu Tahun 2016. Jurnal Kesehatan, 11(1). file:///C:/Users/ACER--

/Downloads/5107-12728-2PB\%20(5).pdf.

Wijaya \& Putri. (2013). Keperawatan medikal bedah 2. Yogyakarta: Nuha Medika.

Wariin, S., \& Pranata, A. E. (2018). Pengaruh penekanan titik akupresur Taixi (Ki3), Sanyinjiao (Sp6) terhadap penurunan 
tekanan darah pada lansia dengan hipertensi di Pstw Jember. Jurnal Kesehatan $\quad d r . \quad$ Soebandi. https://media.neliti.com/media/publicati ons/293154-effect-of-taixi-ki3acupressure-pressure-1703b0ef.pdf

Yang, H., Schnall, P.L., Jauregui, M., Ta-Chen Su., \& Baker, D. (2006). Work hours and self-reported hypertension among working people in california. Diunduh dari www.hypertensinaha.org. 